\title{
The fuzzy logic controllers synthesis method in the vector control system of the wind turbine doubly-fed induction generator
}

\author{
Andrey Uskov ${ }^{1}$, Vadym Shchokin ${ }^{2}$, Oleksii Mykhailenko,", and Oleksii Kryvenko ${ }^{3}$ \\ ${ }^{1}$ Plekhanov Russian University of Economics, Moscow, 117997, Russia \\ ${ }^{2}$ Kryvyi Rih National University, Department of Power Systems and Energy Management, Kryvyi Rih, 50027, Ukraine \\ ${ }^{3}$ Kryvyi Rih National University, Department of Mining Machines, Kryvyi Rih, 50027, Ukraine
}

\begin{abstract}
The article is devoted to the improvement of control systems for wind turbines by developing fuzzy controllers with higher transient characteristics and low computational costs of identification in comparison with the applied PI controllers. Based on the self-organization method, a fuzzy speed controller of the doubly-fed induction generator (DFIG) of a wind turbine was synthesized, which uses a zero-order Sugeno fuzzy inference system and is made in the form of a block-oriented Wiener model. This regulator is an element of the vector control system of the transistor converter on the rotor side. The results of simulation modeling of the fuzzy controller showed that it provides a lower transition time compared to the PI controller, by $53.59 \%$ during acceleration and by $79.76 \%$ during braking, and $23.81 \%$ less error speed deviations from the reference signal. Such indicators can minimize losses while maintaining the maximum output power point of the power plant. The implementation of the developed system on wind turbines contributes to increasing the efficiency of wind farms, reducing the cost of electricity production, reducing the payback period of equipment, and the sustainable development of alternative energy in general.
\end{abstract}

\section{Introduction}

The sharp increase in the number of wind farms integrated into existing power systems has predetermined the need to increase the volume of electricity generation while reducing the reserves of non-renewable fuel and energy resources, as well as the rapid development of the elemental base of power electronics devices used in wind power converters. As a result, in Europe, the share of wind energy in the structure of electricity production approaches $40 \%$, and in some countries, it exceeds this indicator [1].

The main element of a wind farm is a wind turbine, which converts the kinetic energy of the wind flow into electrical energy [2]. For horizontal axis wind turbines, it was established $[2,3]$ that the dependence of the output power of the turbine on the angular frequency of generator shaft rotation is unimodal, and its extremum point drifts with changing wind speed. Thus, to ensure maximum efficiency of electricity generation, it is necessary to be able to adjust the rotation speed of the generator shaft. For this purpose, asynchronous generators made according to the scheme of the doubly-fed induction generator (DFIG) $[4,5]$ are used. The angular frequency of generator rotation, depending on the design, is determined by the difference or the sum of the voltage frequencies supplied to the stator and rotor windings.

At the same time, when finding the extremum point, it is necessary to provide stabilization of the rotation speed.
Given that the wind speed can change quite often and sometimes in a wide range, therefore, high-quality regulation and stabilization of rotation speed, which provides a short transient time, the absence of overshoot and errors in static, will increase the efficiency of electricity production, as a result of reducing losses while ensuring maximum output power of the energy unit. This will contribute to the broader introduction of wind turbines in existing electric networks due to the reduction in the cost of generating electricity and reducing the payback period for the construction of new wind farms. A constant increase in the share of wind energy in the structure of global electricity production will ensure the sustainable development of alternative energy in general.

To regulate the rotation speed of DFIG, the vector control method of the voltage frequency, which is supplied to the rotor winding [4-13].

In such systems, the PI controllers of speed and current are traditionally used [6-13]. Improving the quality of regulation can be achieved using, for example, ARMABIS structures [14] or control systems with a predictive model based on orthogonal functions [15-17], which have high transient rates. More common is the approach that involves the replacement of classical PI controllers with fuzzy logic controllers [18-23].

However, the synthesis of such controllers is a resource-intensive process that requires significant time, material and computational costs and involves the implementation of two stages.

* Corresponding author: epem.mykhailenko@gmail.com 
First, by a preliminary expert assessment, fuzzy production rules of the controller's knowledge base are formed, the type of the fuzzy inference system, and the initial parameters of the controller are selected.

After that, structural and parametric identification of the fuzzy controller is carried out experimentally on a real object or a simulation model. Due to high computational loads, they are limited only by parametric identification.

Thus, the development of a method for the synthesis of fuzzy controllers in the vector control system of the wind turbine doubly-fed induction generator with low computational costs is an urgent task.

\section{The characteristic of the control object}

The structure of the control system for a wind turbine (fig. 1) [6] was adopted as a control object. It consists of an asynchronous generator made according to the scheme of a doubly-fed induction generator (DFIG), the stator of which is connected to the electric power grid through a transformer, and the rotor receives power from the stator circuit through the converter. The converter consists of two bridge circuits with transistor switches with an intermediate DC-link. The speed control of the motor shaft is directly controlled by the converter located on the rotor side. Therefore its control system will be considered in this work.

The control system includes pulse width modulation unit $(\mathrm{PWM})$, coordinate converters $\mathrm{dq} \rightarrow \mathrm{ABC}$ and $\mathrm{ABC} \rightarrow \mathrm{dq}$, which implement the direct and inverse ParkGorev transform, phase-locked loop (PLL), fixing the position of the spatial vector, reactive power calculation unit in the stator circuit $\left(Q_{c}\right.$ calc) and four fuzzy logic controllers - angular speed $\left(\omega_{m}\right)$, stator reactive power $\left(Q_{s}\right)$, active and reactive components of the rotor current $\left(I_{d r}, I_{q r}\right)$.

The analytical model of the system used in the simulation is considered in detail in $[4,6,7]$.

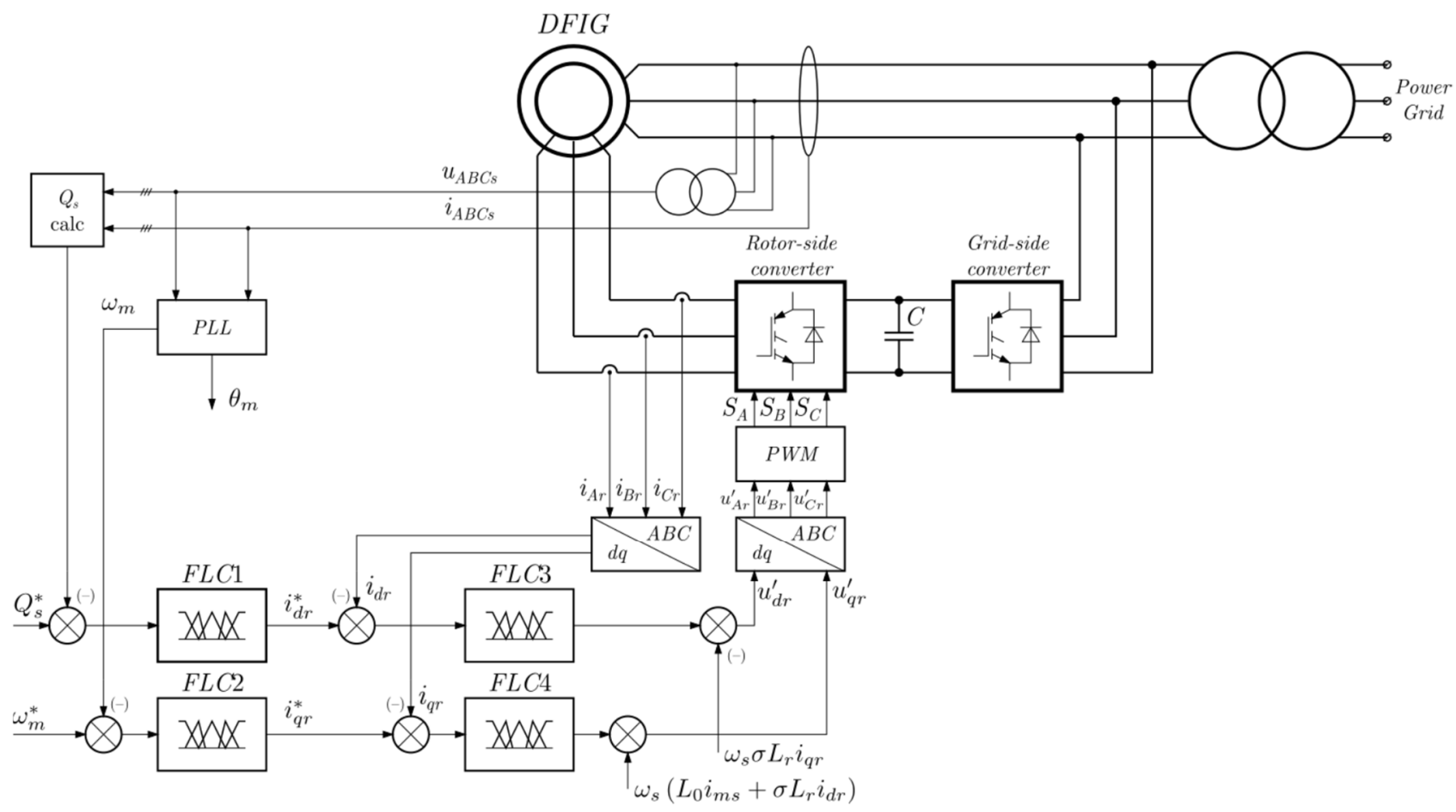

Fig. 1. The block diagram of the vector control system of the rotor-side converter of the wind turbine doubly-fed induction generator.

\section{Synthesis of a fuzzy logic controller of the angular frequency of a wind turbine rotation based on a self-organization algorithm}

In order to simplify, we represent the speed control system of an asynchronous generator in the form of a closed-loop control system with a fuzzy logic controller (FLC) and a wind turbine fig. 2.

The controller is made in the form of a Wiener structure and consists of a linear time-invariant block (LTI) and a fuzzy inference system unit (FIS) [24].

The controller should provide a minimum deviation of the real angular frequency of the wind turbine generator rotation $\omega_{m}$ from speed reference $\omega_{m}^{*}$, which is formed by an extreme regulation system. In this case, it is necessary to maintain acceptable quality indicators of the transition process.

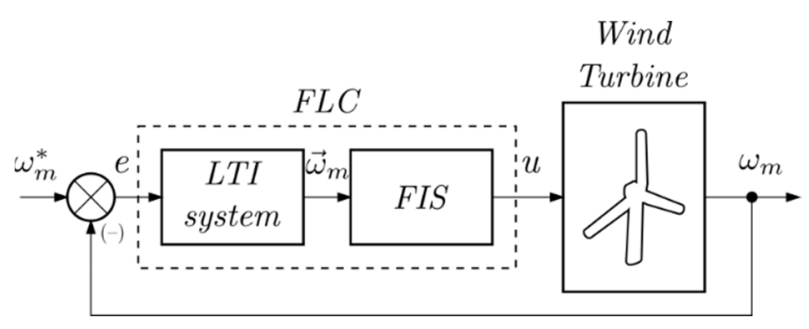

Fig. 2. The control system structure of a wind turbine with a fuzzy logic speed controller. 
It is advisable to evaluate the efficiency of the controller by the mean-square error of a system of the form:

$$
M S E=\frac{1}{n} \sum_{i=1}^{n}\left(\omega_{m}-\omega_{m}^{*}\right)^{2} .
$$

To form a set of fuzzy rules of FIS, it is necessary to have a model that approximates the dynamics of a wind turbine, a set of laws for changing input influences $\omega_{m}^{*}$, by which the quality of the control system with a fuzzy controller is evaluated, and the structure of the LTI block (in the simplest case, LTI should provide for the input of the FIS control error $e$ and its derivative $d e / d t[24,30]$ ).

Discrete fuzzy controller is shown in fig. 3.

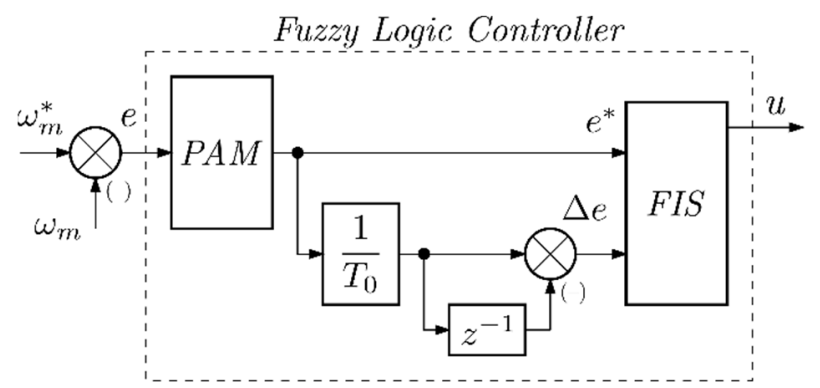

Fig. 3. The block diagram of a shaft speed fuzzy controller of the wind turbine doubly-fed induction generator.

The controller structure includes the PAM block pulse-amplitude modulator with a zero-order lock, described by the equation: $e^{*}(t)=e\left(t_{k}\right)$ with $t \in\left[\begin{array}{ll}t_{k}, & t_{k+1}\end{array}\right]$, where $t_{k}=k \cdot T_{0}$ - is the discrete sampling time, $k=0,1,2, \ldots-$ are the discrete-time samples, $T_{0}=0,1-$ is the sampling period.

The fuzzy inference block of the FIS controller implements the zero-order Sugeno fuzzy inference algorithm [24-27, 30].

Let's apply the complementing-optimizing selforganization algorithm of a fuzzy logic inference system [24, 28, 29]. Reduced computational costs characterize this algorithm compared with the known algorithms for building up fuzzy neural networks.

Let's describe the essence of the algorithm concerning the task of constructing a fuzzy speed controller for the rotation of an electric generator of a wind turbine.

The FIS block implements the static nonlinearity of the block-oriented Wiener system of the form:

$$
u=\varphi\left(\vec{\omega}_{m}\right)
$$

which should minimize the functional $M S E=G\left(\varphi\left(\vec{\omega}_{m}\right)\right)$, characterizing the quality of the control system according to (1).

Let's suppose that in (2) there is a priori information written as a set $N$ fuzzy production rules of the form: $\Pi_{k}$ : IF $\omega_{1}$ is $A_{k 1}$ AND $\omega_{2}$ is $A_{k 2}$ AND ... AND $\omega_{n}$ is $A_{k n}$, THEN $u=u_{k}$, where $k=1,2, \ldots, N-$ is the knowledge base rule number, $\omega_{j}(j=1,2, \ldots, n)$ - are the vector components $\vec{\omega}_{m}, A_{r j}-$ are the fuzzy numbers with membership functions $\mu_{r j}\left(\omega_{j}\right)$.

A priori information may not be available (i.e. $N=0$ ).

Using simulation, the values of functional $M S E=\operatorname{MSE}\left(\varphi\left(\vec{\omega}_{m}\right)\right)$ with the current form of dependency $\omega_{m}=\varphi\left(\vec{\omega}_{m}\right)$ are determined.

The algorithm assumes the following sequence of actions.

Step 0 (preliminary). The parameter $\varepsilon$ is defined, which determines the accuracy of minimizing the error function of the form (1).

The expert method determines the a priori rule base of the fuzzy logic controller, consisting of $N$ fuzzy production rules The current number of rules in the database $N_{i}=N$ is set.

Step 1. If the generated knowledge base is empty go to step 2, otherwise, using the zero-order Sugeno fuzzy inference algorithm and existing production rules, the estimate $\varphi_{N}\left(\vec{\omega}_{m}\right)$ is determined [24,30]:

$$
\varphi_{N}\left(\vec{\omega}_{m}\right)=\frac{\sum_{k=1}^{N} u_{k} \cdot \xi_{k}\left(\vec{\omega}_{m}\right)}{\sum_{k=1}^{N} \xi_{k}\left(\vec{\omega}_{m}\right)},
$$

where $\xi_{k}\left(\vec{\omega}_{m}\right)=\mu_{k 1}\left(\omega_{1}\right) \times \mu_{k 2}\left(\omega_{2}\right) \times \ldots \times \mu_{k n}\left(\omega_{n}\right)$ - is the truth degree of the premises of the $k$-th rule.

According to the estimate (3), the value of the functional $M S E_{N}$ is determined using simulation (see formula (1)).

Step 2. The knowledge base is replenished with a rule of the form: $\Pi_{N+1}$ : IF $\omega_{1}$ is $A_{(N+1) 1}$ AND $\omega_{2}$ is $A_{(N+1) 2}$ AND $\ldots \omega_{n}$ AND $A_{(N+1) n}$, THEN $u=u_{N+1}$, where $A_{(N+1) j}$ - are the fuzzy numbers with triangular membership functions $[24,30]$ :

$$
\mu_{(N+1) j}\left(\omega_{j}\right)= \begin{cases}1-\frac{\left|\omega_{j}-\gamma_{(N+1) j}\right|}{\psi_{(N+1) j}}, & \text { IF }\left|\omega_{j}-\gamma_{(N+1) j}\right| \leq \psi_{(N+1) j}, \\ 0, & \text { IF }\left|\omega_{j}-\gamma_{(N+1) j}\right|>\psi_{(N+1) j},\end{cases}
$$

where $\gamma_{(N+1) j}$ - are the fuzzy number centers $A_{(N+1) j}$.

The formula (3) determines the estimate $\varphi_{N+1}\left(\vec{\omega}_{m}\right.$, $\left.\gamma_{(N+1), 1}, \ldots, \gamma_{(N+1), n}, u_{N+1}, \psi_{(N+1), 1}, \ldots, \psi_{(N+1) n}\right)$. Parameter identification $\gamma_{(N+1) 1}, \ldots, \gamma_{(N+1) n}, u_{N+1}$, $\psi_{(N+1) 1}, \ldots, \psi_{(N+1) n}$ by optimizing the function: $M S E_{N+1}=\operatorname{MSE}\left(\eta_{N+1}\left(\vec{\omega}_{m}, \gamma_{(N+1) 1}, \ldots, \gamma_{(N+1), n}\right.\right.$, $\left.\left.u_{N+1}, \psi_{(N+1), 1}, \ldots, \psi_{(N+1) n}\right)\right)$ by the specified parameters is performed $[24,30]$.

Step 3. Check inequality:

$$
M S E_{N}-M S E_{N+1} \leq \varepsilon,
$$

where $M S E_{N}=\operatorname{MSE}\left(\varphi_{N}\left(\vec{\omega}_{m}\right)\right)$,

$M S E_{N+1}=\operatorname{MSE}\left(\varphi_{N+1}\left(\vec{\omega}_{m}\right)\right)$.

The value of $N$ is incremented: $N=N+1$.

If inequality (5) is not satisfied, go to step 2, otherwise, go to step 4.

Step 4. The knowledge base of the fuzzy logic controller is considered to be formed. The result is a knowledge base consisting of $m$ production rules, while the value of the function is $M S E_{N}$.

The FIS knowledge base of the fuzzy speed controller of an electric wind turbine, obtained by an expert method, is presented in Table 1 .

The membership functions of the fuzzy variables N, Z, and $\mathrm{P}$ have the form shown in fig. 4.

The mean-square error (1) is considered as an indicator of the quality of the control system when a single 
step action is applied to the input of the system $\omega_{m}^{*}=1_{0}(t)$.

Table 1. A set of fuzzy rules of FIS

\begin{tabular}{|lllllll|}
\hline$R 1:$ & IF & $\mathrm{e}^{*}$ & is & $\mathrm{P}$, THEN & $u=1$ \\
\hline$R 2:$ & IF & $\mathrm{e}^{*}$ & is & $\mathrm{N}$, THEN & $u=-1$ \\
\hline$R 3:$ & IF & $\Delta \mathrm{e}$ & is & $\mathrm{P}$, THEN & $u=1$ \\
\hline$R 4:$ & IF & $\Delta \mathrm{e}$ & is & $\mathrm{T}$, THEN & $u=-1$ \\
\hline$R 5:$ & IF & $\mathrm{e}^{*}$ & is & $\mathrm{Z}$, AND $\Delta \mathrm{e}$ is $Z$, THEN & $u=0$ \\
\hline
\end{tabular}

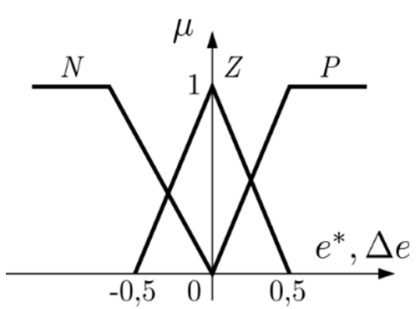

Fig. 4. Membership functions of fuzzy variables $N, Z$ and $P$.

Preliminary modeling of a wind turbine control system, in which a fuzzy logic controller is defined by the five production rules described above, revealed the following result: $M S E=0,00451$.

Then the synthesis in accordance with the described algorithm was performed. A priori knowledge base corresponds to the Table. 1 . The value of the accuracy parameter is $\varepsilon=0,01$.

The added rules are of the form:

$$
\text { IF } e^{*} \text { is } \mathrm{A}_{e k} \text { AND IF } \Delta e \text { is } \mathrm{A}_{\Delta e k} \text {, THEN } u=u_{k} \text {. }
$$

The following parameters of the added rules were optimized: membership function centers $\gamma_{e k}, \gamma_{\Delta e k}$; consequences of the rules $u_{k}$; total dispersion $\psi_{k}$ for both membership functions. As a result of the self-organization algorithm, the following results were obtained: total generated rules considering a priori $N=8$; the value of the mean-square error decreased to $M S E=0,00286$, which is 1,58 times smaller than the original structure of the controller.

\section{Implementation of a fuzzy logic controller of the angular rotation frequency of a wind generator based on a self-organization algorithm}

To conduct a computational experiment to assess the quality of the fuzzy speed controller of DFIG, synthesized by the proposed method, a simulation model of the system was developed in the MATLAB/Simulink/Simscape Power Systems software package. The dynamic model of an electric machine is based on the analytical equations presented in [4, 6]. A generator with a power of $2 \mathrm{MW}$ was adopted as an object. The equivalent circuit of the object parameters was taken from [4, P. 181].

During the experiment, the speed reference signal changed according to the following law: when starting the machine $\omega_{m}^{*}=1$ p.u., which corresponds to the rated rotation speed at the rated wind speed; at 3 seconds, the reference signal step to $\omega_{m}^{*}=0,9$ p.u., and at 6 seconds it steps up to $\omega_{m}^{*}=0,95 p$. u.

Fig. 5 shows the speed transients in control systems using PI and fuzzy logic controllers.

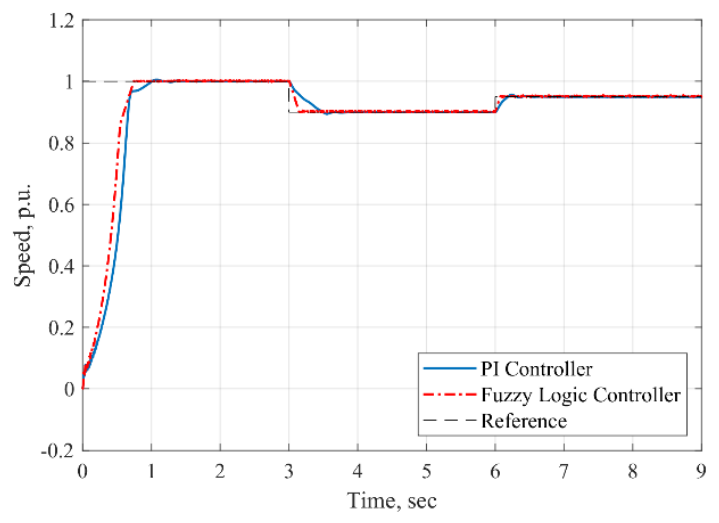

Fig. 5. Speed transients when using a PI controller and a fuzzy logic controller.

The analysis of transient processes in speed shows that the application of the developed fuzzy controller provides the best quality of the control system of wind turbine converter in dynamic modes. Thus, the transient time during the acceleration of the asynchronous dual-supply generator for the fuzzy controller was $0.71 \mathrm{~s}$, which is $53.59 \%$ less than the PI controller, for which this indicator is $1.53 \mathrm{~s}$. When reduced by $3 \mathrm{~s}$, the speed reference signal reaches 0.9 for the compared fuzzy and PI controllers, and the speed was $0.17 \mathrm{~s}$ and $0.84 \mathrm{~s}$, respectively. That is, when the machine brakes, the transition time in the control system with a fuzzy controller is $79.76 \%$ less. Let's also note that when applying the PI controller, overshoot is observed. However, this indicator does not exceed $1 \%$, which is acceptable. There is no error in the statics of both controllers. As a result of the deviation of the object output from the reference signal, $M S E_{F L C}=0,0016$ and $M S E_{P I}=0,0021$ were made. A $23.81 \%$ error reduction indicates the best quality of the proposed zero-order Sugeno fuzzy controller.

Additionally, transient graphs of the main state variables of the DFIG were obtained (fig. 6-15).

Transients in the electromagnetic torque are shown in fig. 6 and fig. 7 .

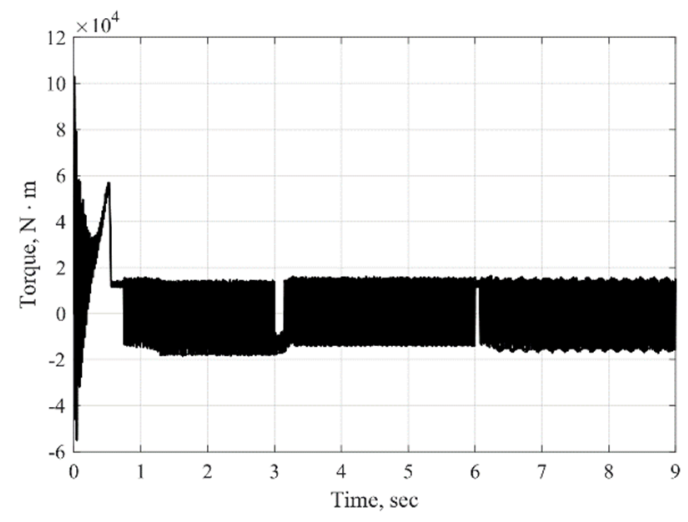

Fig. 6. The torque transient when using the PI speed controller. 


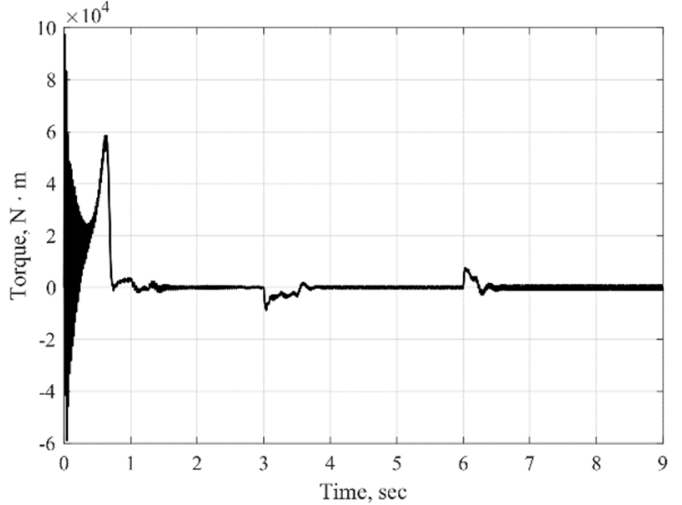

Fig. 7. The torque transient when using a fuzzy logic controller.

The peak value of the electromagnetic torque is $103,445 \mathrm{~N} \cdot \mathrm{m}$ during the acceleration of the motor with a PI speed controller. The use of a fuzzy regulator leads to a decrease in the maximum value of the torque to $97938 \mathrm{~N} \cdot \mathrm{m}$, which is $5.32 \%$ less. At the same time, when the angular velocity is stabilized in a system with a PI controller, torque fluctuations with an amplitude of $18234 \mathrm{~N} \cdot \mathrm{m}$ are observed, which is undesirable. In a system with a fuzzy controller, the oscillation amplitude decreases to $1271 \mathrm{~N} \cdot \mathrm{m}$, i.e., by $93.02 \%$ or 14.35 times.

Transients on the rotor current are shown in fig. 8-11. The use of a PI speed controller leads to oscillations in the d- and q- components of the rotor current (fig. 8). In this case, the amplitude of the q-component oscillations is $2.54 \mathrm{kA}$. This leads to the fact that, in the steady-state, the oscillations of the rotor current have an undamped character (fig. 9). No oscillations are observed in a system with a fuzzy controller, however, when the machine accelerates, the d-component of the rotor current increases to a peak value of $1.17 \cdot 10^{4} \mathrm{~A}$ (fig. 10). This leads to a large current transient (fig. 11). As a result, the transition time in a system with a PI controller is less by $76.62 \%$ (0.54 s).

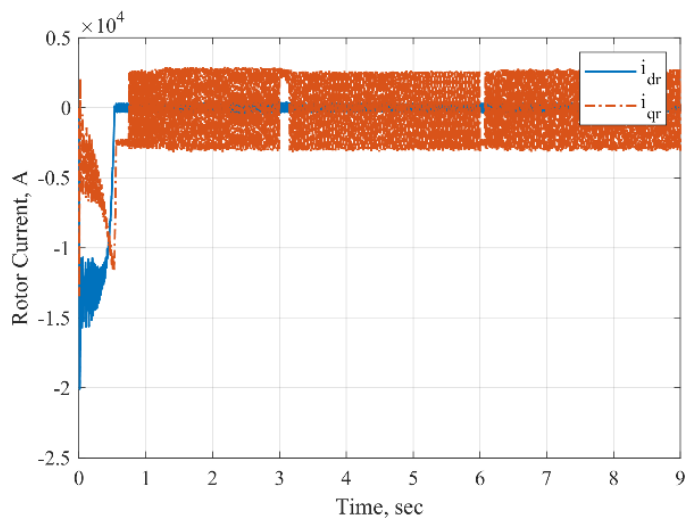

Fig. 8. Rotor current in dq-system using a PI speed controller.

Thus, it is advisable to use the controller of the dcomponent of the rotor current, which is aimed at increasing speed when using a fuzzy speed controller in the vector control system of the converter of an asynchronous DFIG.

Dynamics indicators for currents in stator windings are close to indicators for rotor currents (fig. 12, fig. 13).

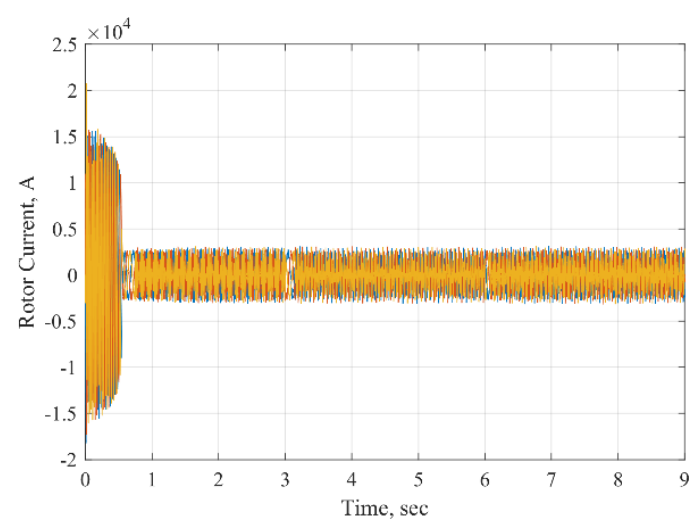

Fig. 9. Rotor currents in ABC-system using a PI controller.

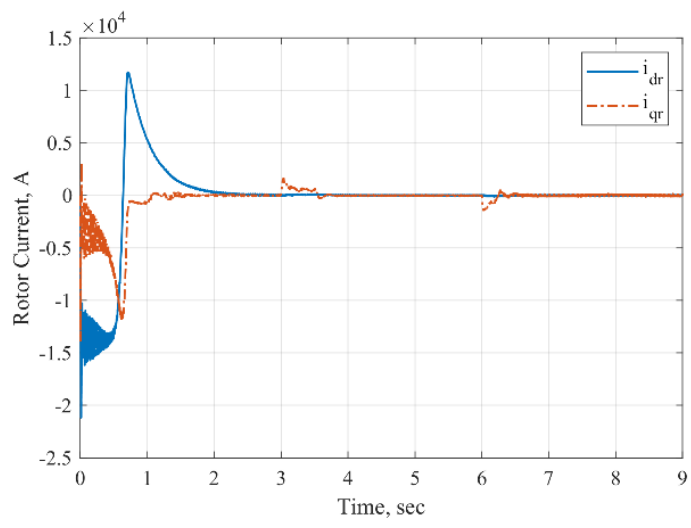

Fig. 10. Rotor currents in dq-system using a fuzzy logic controller.

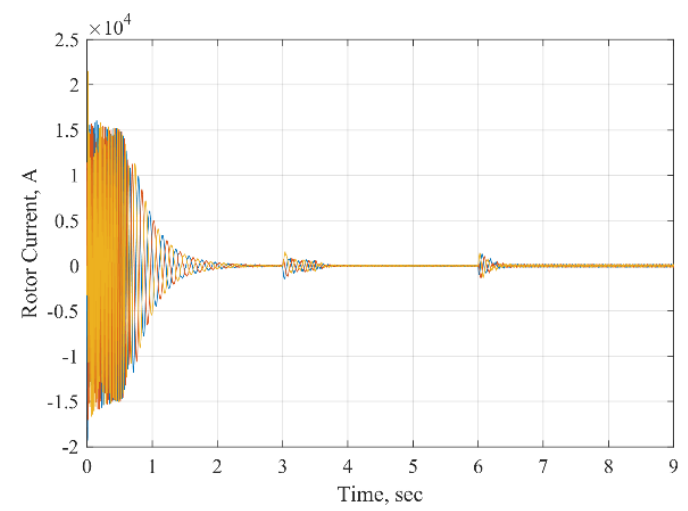

Fig. 11. Rotor currents in ABC-system using a fuzzy logic controller.

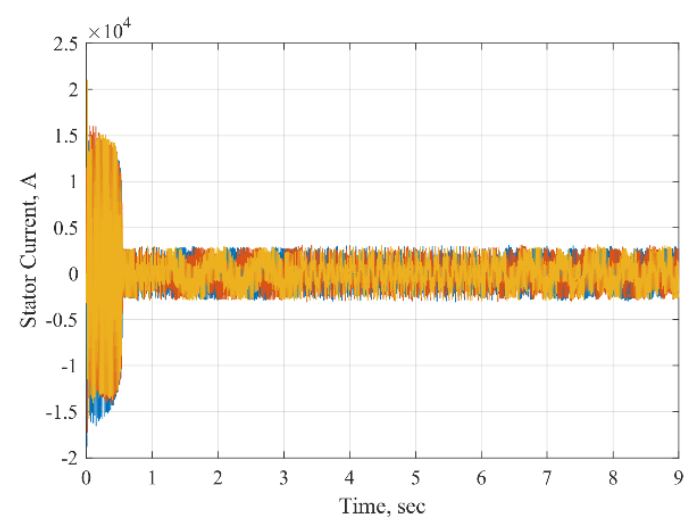

Fig. 12. Stator currents in ABC-system using a PI controller. 


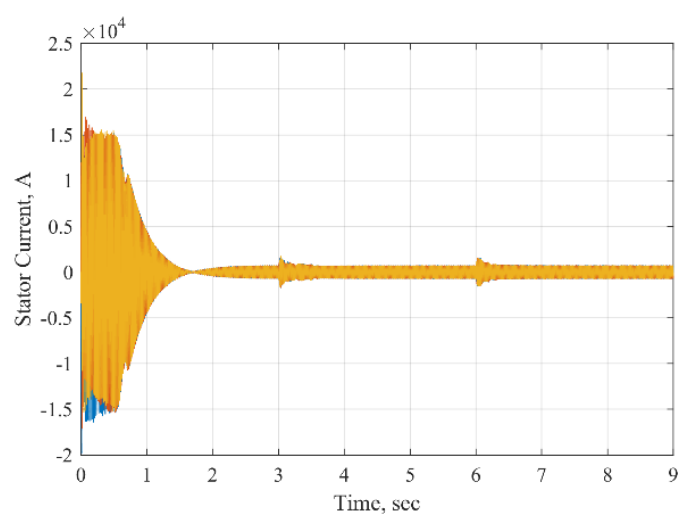

Fig. 13. Stator currents in ABC-system using a fuzzy logic controller.

However, as can be seen from fig. 13, in a system with a fuzzy controller, decreases to $2.14 \mathrm{~s}$ the transition time during acceleration of the machine (in a system with a PI controller $0.54 \mathrm{~s}$, which is $74.77 \%$ less), but there are oscillations with an amplitude of $0.1 \cdot 10^{4} \mathrm{~A}$ in steady states.

Figures 14 and 15 show transients in the d- and qcomponents of the rotor voltage.

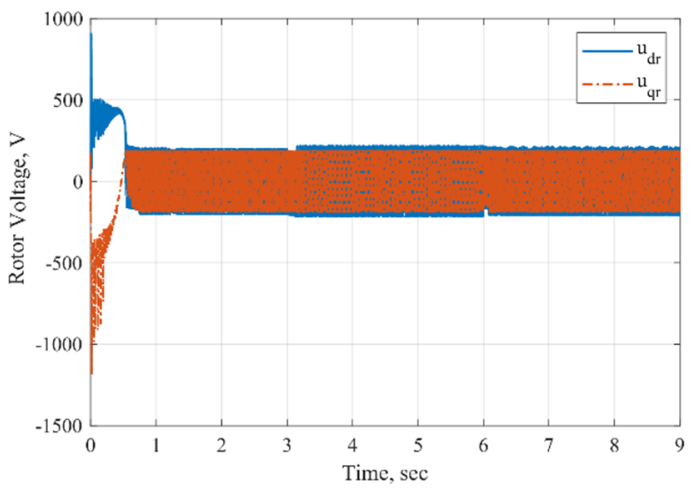

Fig. 14. Rotor voltages in dq-system using the PI controller.

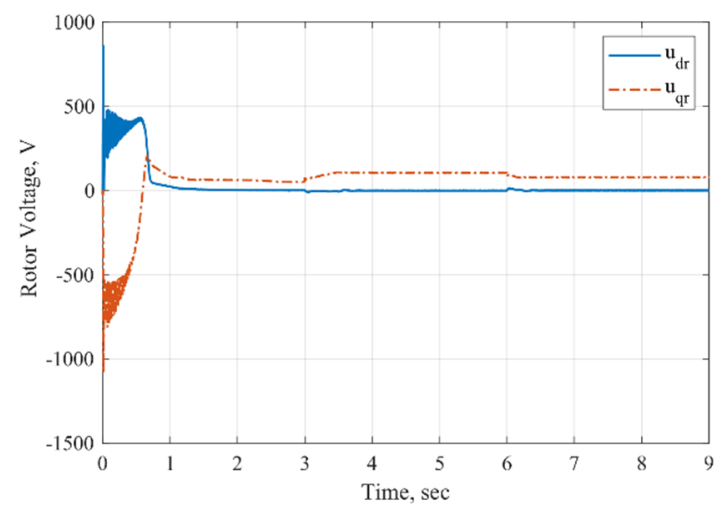

Fig. 15. Rotor voltages in dq-system using a fuzzy logic controller.

When using a PI speed controller, there are oscillations with an amplitude of about $200 \mathrm{~V}$ for both components. In a system with a fuzzy controller, transients are aperiodic.

A comparative analysis of the dynamics of vector converter control systems on the rotor side of asynchronous DFIG with a traditional PI speed controller and a developed fuzzy speed controller, which is based on the Sugeno fuzzy inference system of zero-order and Wiener structure, showed that the latter has mainly the best quality indicators transient processes, both in the controlled variable and in the state variables.

Let's note due to which an improvement in the quality of control when using a fuzzy controller synthesized based on self-organization in comparison with traditional PI controllers is achieved. Firstly, the synthesized fuzzy controller implements a nonlinear control law, has a much larger value of the tunable parameters compared to the PI controller and, as a particular case for specific parameter values, it can also implement the linear PI control law, so, in essence, it can be considered as generalization of the law of PI regulation.

Secondly, due to the use of the synthesis algorithm for the base of fuzzy production rules, it is possible to achieve a structure and parameters of a fuzzy controller that is optimal in terms of quality of control and optimized in terms of system control quality.

Thirdly, the choice of the optimal parameters of a fuzzy controller is, in the general case, a multi-extreme optimization problem. The considered self-organization algorithm allows us to consistently increase the controller's knowledge base, thereby synthesizing by sequentially solving optimization problems of low dimension, which partially avoids such difficulties as high computational costs and falling into local minima during optimization.

\section{Conclusions}

This article proposes a self-organizing method for the synthesis of fuzzy controllers, based on the zero-order Sugeno fuzzy inference system and having the structure of a block-oriented Wiener system for vector control systems for converters of asynchronous DFIG of wind turbines. When analyzing the indicators of control quality, we considered the implementation of a fuzzy controller of the angular frequency of rotation of the shaft of an electric machine. For a comparative analysis, the classic PI speed controller was used. The results of experimental studies made it possible to establish that the synthesized fuzzy controller provides a shorter transition time in terms of speed, the absence of overshoot, and a smaller standard error in comparison with the PI controller.

The algorithm that synthesizes a fuzzy controller based on the self-organization method is simple and has a low computational load, which allows it to be implemented using digital control devices.

The introduction of vector control systems with fuzzy regulators on wind turbines will allow for high accuracy of regulating the speed of the generator shaft speed while maintaining maximum output power in conditions of changing wind speed. This will increase the efficiency of converting the energy of the wind flow into electrical energy and reduce the cost of generation. The result is a reduction in the payback period of the conversion equipment, and, as a result, an increase in the number of wind farms, which will contribute to the sustainable development of alternative energy. 
Subsequent studies will be devoted to the analysis of the dynamic stability of the power grid, which integrates wind turbines using the proposed fuzzy logic controllers.

\section{References}

1. I. Komusanac, D. Fraile, G. Brindley, Wind Energy in Europe in 2018. Trends and Statistics (Wind Europe, Brussels, Belgium, 2019), https://windeurope.org/wpcontent/uploads/files/aboutwind/statistics/WindEurope-Annual-Statistics2018.pdf. Accessed 16 Dec 2019

2. S. Heier, Grid Integration of Wind Energy: Onshore and Offshore Conversion Systems, 3rd edn. (John Wiley \& Sons, Chichester, 2014)

3. O. Anaya-Lara, N. Jenkins, J.B. Ekanayake, P. Cartwright, M. Hughes, Wind Energy Generation: Modelling and Control (John Wiley and Sons, Chichester, 2009)

4. G. Abad, J. López, M. A. Rodríguez, L. Marroyo, G. Iwanski, Doubly Fed Induction Machine: Modeling and Control for Wind Energy Generation (John Wiley \& Sons, Hoboken, 2011)

5. A.A.B. Mohd Zin, H.A. Mahnoud Pesaran, A.B. Khairuddin, L. Jahanshaloo, O. Shariati, Renewable and Sustainable Energy Reviews 27, 692 (2013)

6. H. Abniki, M. Abolhasani, M.E. Kargahi, Energy and Power 3(2), 18 (2013)

7. H. Abu-Rub, M. Malinowski, K. Al-Haddad, Power Electronics for Renewable Energy Systems, Transportation and Industrial Applications (John Wiley \& Sons, Chichester, 2014)

8. K. Kerrouche, A. Mezouar, Kh. Belgacem, Energy Procedia 42, 239 (2013)

9. P. Chakravarty, G.K. Venayagamoorthy, in 2011 IEEE International Electric Machines Drives Conference (IEMDC) (2011), pp. 723-728

10. O.P. Bharti, R.K. Saket, S.K. Nagar, in 2015 39th National Systems Conference (NSC) (2015), pp. 1-6

11. J.L. Domínguez-García, O. Gomis-Bellmunt, L. Trilla-Romero, A. Junyent-Ferré, Computers \& Mathematics with Applications 64, 102 (2012)

12. I. Khan, K. Zeb, W.U. Din, S.U. Islam, M. Ishfaq, S. Hussain, H.-J. Kim, Energies 12, 454 (2019)

13. K. Bedoud, M. Ali-rachedi, T. Bahi, R. Lakel, Energy Procedia 74, 211 (2015)

14. V. Shchokin, O. Shchokina, S. Berezhniy, Metallurgical and Mining Industry 2, 19 (2015)

15. O. Mykhailenko, Eastern-European Journal of Enterprise Technologies 4, 30 (2015)

16. F.D. Adegas, R. Wisniewski, L.F.S. Larsen, in 2013 American Control Conference (2013), pp. 653-658

17. M.A. Benlahrache, S. Othman, N. Sheibat-Othman, in 2015 European Control Conference (ECC) (2015), pp. 3653-3658
18. O. Zamzoum, Y.E. Mourabit, M. Errouha, A. Derouich, A.E. Ghzizal, Energy Science \& Engineering 6, 408 (2018)

19. K. Belmokhtar, M.L. Doumbia, K. Agbossou, in 2012 IEEE International Symposium on Industrial Electronics (2012), pp. 1888-1893

20. B. Hamane, M. Benghanemm, A.M. Bouzid, A. Belabbes, M. Bouhamida, A. Draou, Energy Procedia 18, 476 (2012)

21. H.-L. Fu, H.T. Thien, in AETA 2013: Recent Advances in Electrical Engineering and Related Sciences, ed. by I. Zelinka, V.H. Duy, J. Cha (Springer, Berlin, Heidelberg, 2014), pp. 85-92

22. N. Kumar, R.A. Jaswal, International Journal of Science Technology \& Engineering 3(1), 287 (2016)

23. J. Trivedi, T. Agarwal, IOSR Journal of Electrical and Electronics Engineering 12(5), 21 (2017)

24. A.A. Uskov, Pribory i Sistemy Upravleniya 1, 16 (2004)

25. T. Takagi, M. Sugeno, IEEE Transactions on Systems, Man, and Cybernetics SMC-15, 116 (1985)

26. K. Tanaka, M. Sugeno, Fuzzy Sets and Systems 45, 135 (1992)

27. I.M. Makarov, V.M. Lokhin (eds.), Intellektualnye Sistemy Avtomaticheskogo Upravleniia (Intelligent automatic control systems). (FIZMATLIT, Moscow, 2001)

28. D.A. Linkens, M.F. Abbod, in International Conference on Control 1991. Control '91 (1991), pp. 971-976

29. C.-L. Chen, Y.-M. Chen, Computers in Industry 22, 249 (1993)

30. V.V. Kruglov, M.I. Dli, Intellektualnye informatcionnye sistemy: kompiuternaia podderzhka sistem nechetkoi logiki $i$ nechetkogo vyvoda (Intelligent information systems: computer support for fuzzy logic and fuzzy inference systems). (FIZMATLIT, Moscow, 2002) 